\title{
Research Article \\ Users' Personal Conceptions of Usability and User Experience of Electronic and Software Products
}

\author{
-Tim R. HaAksma, Menno D. T. de Jong ${ }^{\mathbb{D}}$, and Joyce KarReman
}

\begin{abstract}
Research problem: Despite the abundance of research into usability and user experience (UX), there is still debate about the relationship between both concepts. The user perspective is underrepresented in all discussions. This study examines the personal conceptions that users of electronic and software products have of usability and UX.

Research questions: 1. How do users of electronic and software products conceptualize usability and UX? 2. What do they think is the relationship between both concepts? Literature review: We review the literature on conceptualizations of usability and UX and their relationship. The literature suggests that both concepts are still developing and that there are different views about their relationship. A personal-constructs research approach appears to be a fruitful way of shedding more light on this. Methodology: Twenty-one participants were asked to place up to eight products in a grid with two axes: usability (high-low) and UX (high-low). They then filled out a short questionnaire about the products. Finally, interviews were held about their decisions and their views on usability and UX. Results and conclusions: A weak positive correlation between products' usability and UX scores indicates that the relationship between both concepts is far from straightforward. An analysis of the four quadrants of the grid provides a first typology of products based on how users perceive their usability and UX. When reflecting on the relationship between the two concepts, most participants see usability as a part of or contributing to UX. Based on our findings, however, it seems risky to assume that usability is sufficiently covered by the overall concept of UX.
\end{abstract}

Index Terms-Electronic products, personal constructs, software, usability, user experience, UX.

he concepts of usability and user experience (UX) are central to the field of technical communication. Much of the work of technical communicators involves contributing to the usability and UX of products, by developing high-quality user support or by participating as user advocates in product design processes [1], [2]. The two concepts also serve as quality criteria for user support; in particular, usability is frequently used in that way [3], [4]. In a historical overview, Redish shows how technical communication, usability, and UX have developed in close connection over time [5]. Baehr's study of industry leaders demonstrates that usability and UX are, in practice, directly related to interface design, information design, and technical communication [6]. After analyzing industry job postings, Lauer and Brumberger conclude that "technical

Manuscript received April 7, 2017; revised December 15, 2017; accepted December 15, 2017. Date of publication February 19, 2018; date of current version May 22, 2018. (Corresponding author: Menno D. T. de Jong.)

The authors are with the Department of Communication Science, University of Twente, Enschede 7500 AE, The Netherlands (email: t.r.haaksma@utwente.nl;

m.d.t.dejong@utwente.nl; j.karreman@utwente.nl). communication work shares traits and competencies with the field of UX" [7, p. 248].

The academic literature on usability and UX has flourished in the past decade. A search on the Web of Science using the title word "usability" results in 4360 hits since 2007; a search using the title words "user experience" or "UX" yields 1082 hits in the same period. However, the usability and UX literature is dominated by three types of contributions: articles reporting specific usability or UX projects (e.g., [8], [9]); articles investigating the methodology of user-centered design, usability evaluation, or UX research (e.g., [10]-[12]); and nonempirical conceptual pieces (e.g., [13], [14]). Empirical contributions focusing on the demarcation of the concepts of usability and UX, their relationship, antecedents, and consequences are still underrepresented. The user perspective of the concepts is especially underrepresented. In this study, we will focus on the demarcation of and relationship between usability and UX.

The concepts of usability and UX have been discussed extensively in the literature. Usability is known as the extent to which a product effectively, efficiently, and satisfactorily helps users to achieve their goals [15], while UX is generally seen as people's perceptions and responses resulting from 


\section{Practitioner Takeaway}

- This study examines the personal conceptions users of electronic and software products have of usability and user experience (UX).

- The literature suggests that both concepts are still developing and that there are different views about their relationship.

- When reflecting on this relationship, most participants in this study see usability as a part of or contributing to UX. Based on our findings, however, it seems risky to assume that usability is sufficiently covered by the overall concept of UX.

the (anticipated) use of a product [16]. Although both concepts play an important role in research and are widely used in practice, they are still developing. Definitions of usability are sometimes seen as rather general [17], and definitions of UX are often associated with a variety of meanings [18]. A clear view on the relationship between usability and UX is lacking [19], [20]. It seems important to further examine both concepts, their boundaries, and relationship. Doing so will contribute to our understanding of the concepts and help both researchers and practitioners in applying them more accurately in appropriate situations.

To accomplish this goal, we need a research approach that explores the concepts of usability and UX in depth. One way to do this is to elicit personal constructs. This approach assumes that people form their own constructs to make sense of the world that they live in [21] and makes it possible to evaluate products based on dimensions that are salient to users, which, in turn, enables us to study these dimensions themselves. When combining usability and UX, personal constructs research can contribute to our insights about the relationship between both concepts.

Because the user perspective is currently underrepresented in discussions about the concepts of usability and UX, our study aims to identify the personal usability and UX constructs that users have in mind when thinking about the electronic and software products that they use, and how they relate usability and UX to each other. The following research questions will be addressed:

RQ1. How do users of electronic and software products conceptualize usability and UX?

RQ2. What do they think is the relationship between both concepts?

By using a grid in which users were asked to place electronic and software products, we explore how users conceptualize and relate usability and UX.
The study focuses on electronic and software products, as much of the work on usability and UX involves these product categories.

\section{LITERATURE REVIEW}

Researchers have suggested several perspectives on the definitions of usability and UX. Both concepts have also received some criticism and have their own specific problems. In this section, current perspectives on usability and UX will be discussed, followed by a brief overview of what is known about their relationship. Finally, earlier research regarding personal constructs will be reviewed.

Usability The concept of usability went through many developments since its introduction. The definition started as a measurement of ease of use and has been developing ever since [17]. These days, usability includes not only ease of use, but also factors of efficacy and appreciation. Shackel provided one of the early definitions of usability in 1984:

The capability in human functional terms to be used easily (to a specified level of subjective assessment) and effectively (to a specified level of performance) by the specified range of users, given specified training and user support, to fulfil the specified range of tasks, within the specified range of environmental scenarios. [21, commented on p. 731]

Other characteristics were later identified by Nielsen, who argued that usability is not a one-dimensional property and that it should be defined using measurable aspects [22]. He described five attributes of usability: learnability, efficiency, memorability, errors, and satisfaction. According to Nielsen and Levy, usability itself cannot be measured, but it has several measurable parameters [23]. These parameters can be divided into two categories: subjective user experiences and objective performance. 
A definition of usability was later provided by the International Organization for Standardization (ISO):

The extent to which a product can be used by specified users to achieve specified goals with effectiveness, efficiency and satisfaction in a specified context of use. [23]

This definition underwent several revisions. One revision added understandability, learnability, operability, attractiveness, and usability compliance to the definition [25]. This version was later revised to include accessibility and user error protection, while removing usability compliance [15]. The ISO also renamed attractiveness as user interface aesthetics and understandability as appropriateness recognizability. These revisions exemplify how the concept has been (and still is) in development.

The concept of usability has encountered several problems. Many usability definitions describe the concept well but do not specify usability in quantifiable or measurable terms [17]. Some researchers claim that this is what makes usability difficult or even impossible to define: Usability is an emerging property that depends on interactions among users, products, tasks, and environments, rather than a specific property of a person or thing [12]. Another view is that usability does not exist in an absolute sense, but only in reference to particular contexts. Trying to measure the various aspects can then vary widely-for example, depending on the type of tasks that must be carried out with a product [26].

The problems in specifying and measuring usability have resulted in diverging conceptualizations. Examples can be found in usability studies of embedded systems, where specific aspects of usability vary among different kinds of devices and systems [27]. Other researchers make more general distinctions, for instance, by defining summative (focusing on measuring overall task execution) and formative (focusing on diagnosing problems and optimizing products) conceptualizations of usability [12]. In yet another example, the usability concept is approached through different analytical lenses, in which each lens emphasizes different issues or outcomes [28].

Several diverging conceptualizations exist in the literature, and consensus has yet to be reached. Although the most recent ISO definition [15] is making progress in this direction, usability remains a topic of debate. Research still calls for a clearer scope of usability [12]. Achieving that goal, is complicated, not only due to the ongoing development of usability itself, but also due to the rise of related concepts such as UX.

User Experience UX is a more recent and broader concept than usability. Its broadness is already visible in one of the early descriptions of experience in relation to products:

By "experience," we mean all the aspects of how people use an interactive product: the way it feel in their hands, how well they understand how it works, how they feel about it while they're using it, how well it serves their purposes, and how well it fits into the entire context in which they are using it. [29, p. 12]

Early UX research used labels such as pleasurable products, hedonic quality, and engineering joy [30], or qualities such as beauty and other noninstrumental needs [31]. The concept has gone through a lot of development ever since.

UX can be seen as a response to usability. Early UX literature argued that usability research focuses too strongly on task efficiency and work [30], and research into human-computer interaction (e.g., usability testing) concentrates too much on instrumental factors [31]. More encompassing notions of product quality were needed.

UX is commonly seen as a concept that fits this notion of all-encompassing quality. It focuses on the interaction between people and products, and all sorts of experiences that result from it. These may include physical, sensual, cognitive, emotional, and aesthetic aspects [18]. It can be seen as a more momentary, evaluative feeling while interacting with a product or service. This approach shifts attention away from the product itself to the subjective human and emotional side of product use [32]. UX highlights nonutilitarian aspects of interactions with products, and emphasizes user affect, sensation, and the meaning and value of such interactions in everyday life [33]. These perspectives on UX are reflected in the following ISO definition:

A person's perceptions and responses resulting from the use and/or anticipated use of a product, system, or service. [16]

This definition suggests that UX encompasses a wide range of user-related aspects (e.g., emotions, beliefs, preferences) before, during, and after use. It 
also assumes that UX is a consequence of many interrelated factors related to system, user, and context [31]. An example of such interaction is given in a study on online games, where UX was affected by the extent to which a product met users' expectations [34].

Like usability, the concept of UX poses several problems. The main criticism involves its vagueness [31]. Because of its broadness and malleability and the complex research landscape, it is difficult to reach a universal definition of UX. UX is often associated with a wide range of meanings [18]. There is neither a consensual definition nor a coherent theory [33].

Some researchers have attempted to keep track of the different perspectives among UX researchers and practitioners. They showed that UX is dynamic, context-dependent, and subjective [33]. User-related and contextual factors are seen as important variables in the shaping of UX [19]. There is divergence in preferred definitions between and among researchers and practitioners [19], [33].

More research into the boundaries of UX is needed. Although attempts have been made to create a general understanding, parts of the concept remain unclear. Researchers call for better definitions of the nature and scope of UX [33], and a better understanding of different perspectives in order to improve UX activities [19].

\section{Relationship Between Usability and UX Since}

UX started out as a response to usability, a relationship between the concepts is generally assumed. However, with both concepts going through their own developments, the exact relationship is quite unclear.

The ISO definition of UX [16] notes that usability criteria can be used to assess aspects of UX. It also states that-when interpreted from the perspective of users' personal goals-usability may include perceptual and emotional aspects that are typically associated with UX. Such overlapping aspects raise questions about the boundaries of and relationship between the two concepts. Many researchers and practitioners see usability as a part of UX [19], [20], or assume that usability is a condition for positive UX [19]. However, there are also perspectives suggesting that usability is not necessarily the main condition [20].

Bevan described three views of the relationship between UX and usability [35]: UX as an elaboration of the satisfaction component of usability [36], UX as something distinct from usability [37], or UX as an umbrella term for all users' perceptions and responses (both subjective and objective). This last perspective seems to be most in line with the previously mentioned ISO definition of UX [16]. Koruso tried to characterize the relationship between usability and UX by situating UX in an artifact's quality in use, and situating usability as one of the many aspects of objective artifact quality [38].

Other studies reveal more details about the relationship. For instance, a strong relationship was found between users' perceptions of the aesthetics of an interface and their perceptions of the system's usability [39]. Another study on the same topic, however, showed that increased product aesthetics do not necessarily lead to an improvement of objective measures of usability, such as task-completion time [40]. Yet, another study showed that users' perceptions of the instrumental qualities of a system may affect their emotional reactions [41].

It can thus be concluded that more research is needed on the relationship between usability and UX. Though the previous literature shows that most perspectives see usability as related to UX, it is still unclear what this relationship truly means and which perspective applies to which situation.

Personal Constructs One of the ways to examine the concepts of usability and UX in detail is by using Personal-Construct Theory. This theory states that people make sense of the world through their own constructs, rather than through concepts that exist independently of them [21]. Personal constructs are not always consistent with each other, and can be used both explicitly and implicitly.

Earlier studies of personal usability or UX constructs have mainly investigated how professionals think about usability and UX, or how people with different cultural backgrounds or other characteristics make sense of them [42]-[45]. This has resulted in overviews of the concepts as employed by different groups. Usability professionals, for instance, appear to use conceptions of usability that go beyond the ISO definition [43]. Personal constructs of usability are richer than the concept as originally defined [45]. For example, there appear to be notable differences between users and developers. When it comes to usability, users relate ease with leisure and 


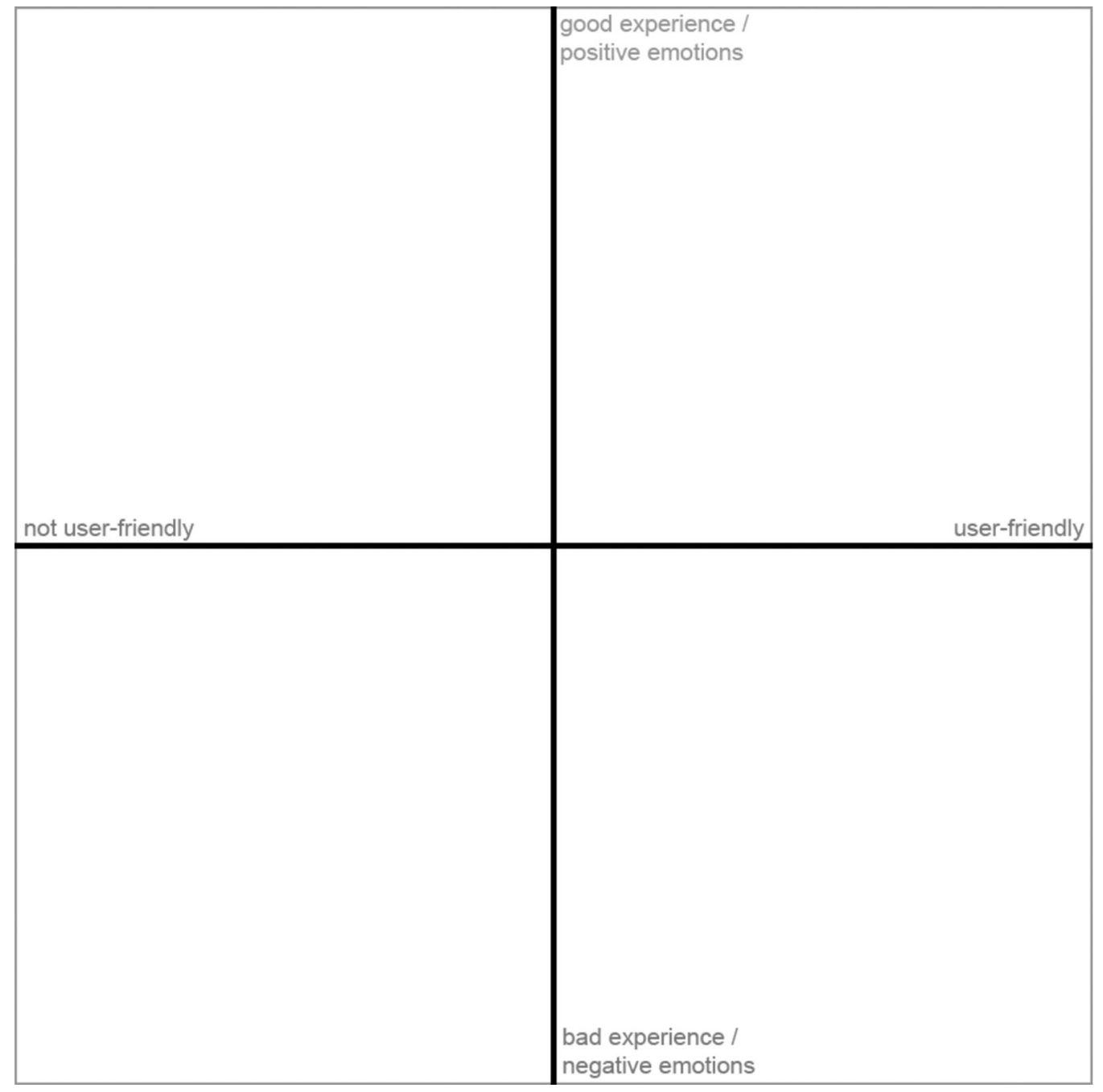

Fig. 1. Usability/UX Grid.

frustration with work, and have different notions of usefulness than developers [44]. Regarding UX, users focus more on context-related constructs than developers, who seem to be more concerned with getting the work done [42].

Since both usability and UX focus strongly on users, it seems important to know more about how users make sense of these concepts. Personalconstructs research shows that the elicited constructs are sometimes difficult to reconcile with prevailing definitions and, thus, call for an extension of current work [42]. In this study, we use a personal-constructs approach to explore the relationship between usability and UX.

\section{Methodology}

To investigate personal conceptions of usability and UX, we designed a method combining qualitative and quantitative elements. The central element in our data collection was a grid on which participants were asked to place specific electronic and/or software products. This technique was complemented by a brief questionnaire about the products and a face-to-face interview. The study was approved by the Ethical Committee of the University of Twente.

Usability/UX Grid We did not want to gather generic information about usability and UX, but aimed for usability and UX perceptions about specific products. As a result, the main element of our study was a grid (see Fig. 1). We wanted participants to reflect on the usability and UX of particular electronic and software products that they use. The grid consists of a horizontal axis for usability (from "not user-friendly" to "user-friendly") and a vertical axis for UX (from good "experience/positive emotions" to "bad 
experience/negative emotions"). To avoid the risk of participants referring to any prior knowledge about the constructs, we avoided the terms "usability" and "UX."

The grid was accompanied by written instructions. The instructions emphasized that participants should list up to eight electronic or software products about which they had rather strong feelings, not specifying whether these feelings should be positive or negative. The instructions also provided product examples in several categories to help participants get started. The examples were broad, ranging from common household electronics, to smart devices, to both common and more sophisticated software and apps. Participants had to write down the name of products on the form and then could place them somewhere in the grid with a point and a number referring to the form. The main aim of including this broad range of products and allowing participants to pick them on their own was to ensure that the products would be meaningful enough to be discussed in-depth during the following interview.

Questionnaire We also administered a short questionnaire about the products placed in the grid. Participants were asked to give an overall assessment of the quality (overall grade) for each product (on a scale from 1 to 10). They were also asked four more specific questions using five-point Likert scales.

- This product is (or was) important to me in daily life.

- I make good use of all the functions that this product has to offer.

- Having a good user-friendliness is important for this product.

- Giving good experiences and positive emotions is important for this product.

Interview Finally, semistructured interviews were conducted to elicit detailed personal usability and UX conceptions. First, participants were asked to explain the place of each product in the grid. Then, the interview continued with a discussion of the four quadrants of the grid. Participants were asked what the products in each quadrant had in common, and what distinguished them from products in other quadrants. Optional questions were asked when participants left a quadrant empty or listed only a single product in a quadrant. Then, we asked questions about the reasons for smaller differences within the quadrants. The interview ended with questions about participants' personal views about the concepts of user-friendliness and positive/negative user experiences.

Procedure The study was conducted in quiet rooms with the same setup for each participant. To avoid potential bias, the study was titled "How people think about electronic and software products." After a brief introduction, participants signed a consent form and then moved to the three main parts of the research, as described above. Toward the end of the sessions, participants answered demographic questions regarding age, gender, and education. Finally, we debriefed them, including an explanation of the goal of the research and the opportunity for them to ask any questions. On average, sessions took around an hour per participant. The grid and questionnaire were completed on paper; the interviews were audio recorded.

Participants The participants for the study were 21 university students from various technical and nontechnical programs. There were more male than female participants (14 versus 7 ). All participants were aged 18 or above (mean age $=23, \mathrm{SD}=5.6$ ). Participants were found through a participant pool or were invited personally. Participants recruited through the participant pool received participant credits, which the students are required to gather as a part of their education. Participants recruited by personal invitation received no compensation.

Data Analysis The quantitative data from the grid and the questionnaire were analyzed using SPSS. Our analyses focused on the correlation between products' usability and UX scores, and on the characteristics of the products in the four quadrants of the grid. Characteristics of the product were analyzed using the scores on the questionnaire (overall quality, importance in daily life, proportion of functionality used, importance of usability, and importance of UX).

In addition, we categorized all products as being hedonic (mainly used for leisure or entertainment), utilitarian (mainly used for performing certain tasks), or both (applicable for both hedonic and utilitarian use). This coding was done by two independent coders. The intercoder agreement was good (Cohen's kappa $=0.84$ ); differences in coding were discussed and led to adaptations. The results were translated into two dichotomies, with each product receiving a hedonic $(0 / 1)$ and utilitarian (0/1) score. 


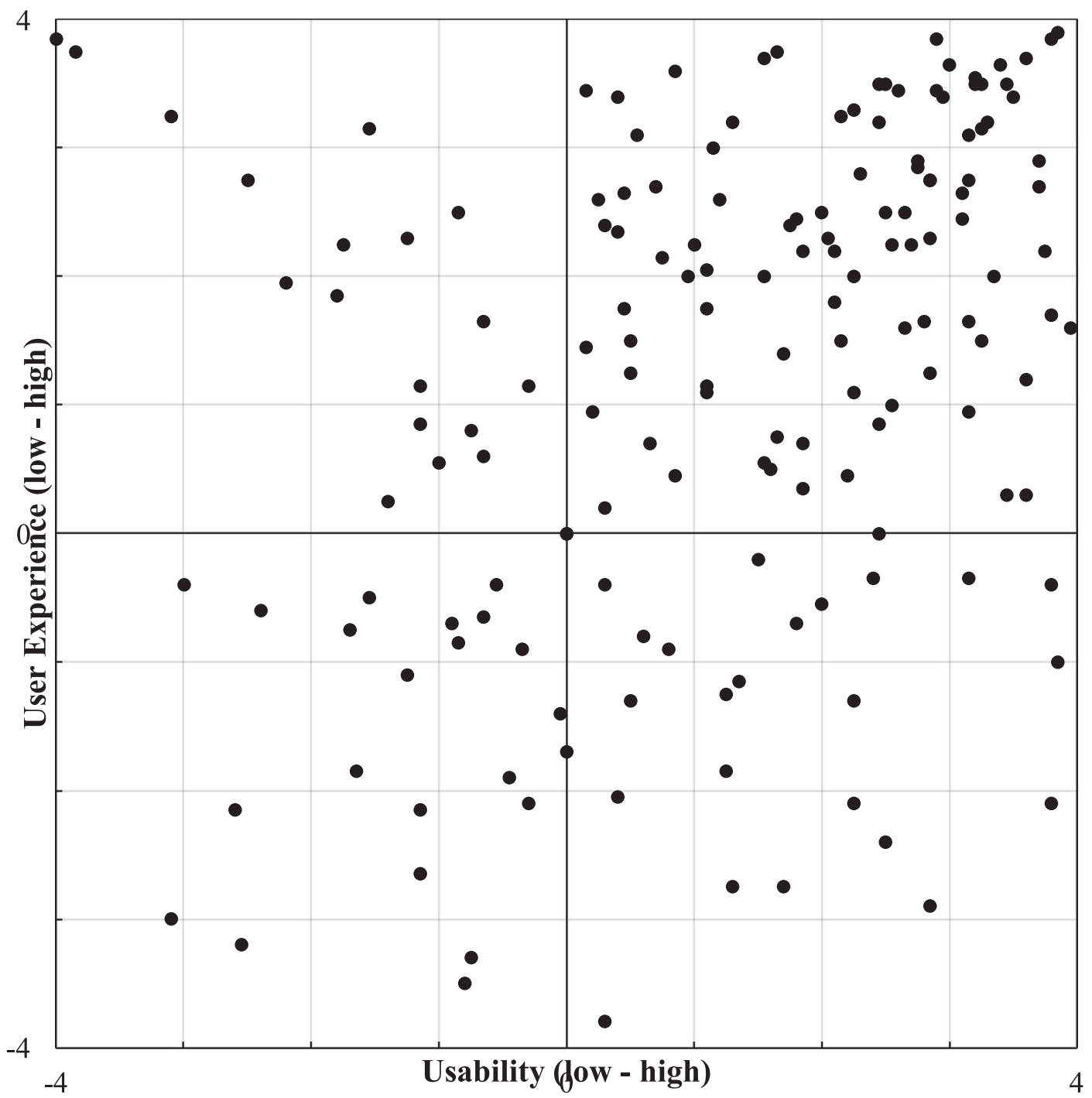

Fig. 2. Scatter plot of all products placed in the grid.

Data from the interviews were transcribed verbatim. There were three levels of coding. First, assertions about products were organized and summarized by quadrant. Second, assertions about similarities of and differences between quadrants were coded and compared. Third, assertions reflecting participants' views of the concepts of usability and UX, throughout the interviews but, in particular, as a response to the final interview questions, were coded separately. Statements in the transcripts were filtered using the keywords used for usability ("user-friendly") and UX ("experience" and "emotion"). These statements were coded based on whether or not the participant explicitly mentioned aspects relevant to the concepts of usability or UX. This coding process was performed by two coders using the filtered statements of four randomly selected participants, with satisfactory intercoder agreement (Cohen's kappa $=0.74)$. Again, differences in coding were discussed and led to adaptations of the coding scheme.

\section{Results}

In total, 165 products were listed in the grid and discussed during the interviews $(7.8$ per participant). Fig. 2 gives a scatter plot of all products in the grid. Most products (60\%) were located in the upper-right quadrant (high usability, high UX). Fewer products were placed in the other three quadrants: $13 \%$ in the lower left quadrant (low usability, low UX), 11\% in the upper left quadrant (low usability, high UX), and 14\% in the lower-right quadrant (high usability, low UX). A weak positive correlation was found between the usability score and the UX score of products $(r=$ 
TABLE I

RELATIONSHIP BETWEEN USABILITY SCORE AND HEDONIC/UTILITARIAN NATURE OF PRODUCTS

\begin{tabular}{lcc}
\hline & \multicolumn{1}{c}{$\begin{array}{c}\text { Positive usability } \\
\text { score (right quadrants) }\end{array}$} & $\begin{array}{c}\text { Negative usability } \\
\text { score (left quadrants) }\end{array}$ \\
\hline $\begin{array}{l}\text { Hedonic } \\
\text { characteristics }\end{array}$ & $62(50 \%)$ & $14(36 \%)$ \\
$\begin{array}{l}\text { Utilitarian } \\
\text { characteristics }\end{array}$ & $106(86 \%)$ & $31(80 \%)$ \\
\hline
\end{tabular}

Note: The number and percentage express the proportion of products with hedonic or utilitarian characteristics in the right or left quadrants of the grid. Percentages add up to more than $100 \%$ because products could have both characteristics.

TABLE II

RELATIONSHIP BETWEEN UX SCORE AND HEDONIC/UTILITARIAN NATURE OF PRODUCTS

\begin{tabular}{lcc}
\hline & $\begin{array}{l}\text { Positive UX score } \\
\text { (upper quadrants) }\end{array}$ & $\begin{array}{c}\text { Negative UX score } \\
\text { (lower quadrants) }\end{array}$ \\
\hline $\begin{array}{l}\text { Hedonic } \\
\text { characteristics }\end{array}$ & $66(56 \%)$ & $11(24 \%)$ \\
$\begin{array}{l}\text { Utilitarian } \\
\text { characteristics }\end{array}$ & $95(81 \%)$ & $42(93 \%)$ \\
\hline
\end{tabular}

Note: The number and percentage express the proportion of products with hedonic or utilitarian characteristics in the upper or lower quadrants of the grid. Percentages add up to more than $100 \%$ because products could have both characteristics.

0.33, $p<0.05)$. This finding suggests that it is wise to see the two concepts as related but separate entities. Usability seems to be neither a sufficient nor a necessary condition for UX.

Quantitative Results Our first analyses involve the relationship between usability/UX and the hedonic and utilitarian nature of products. Table I compares the products with high and low usability scores. We did not find significant differences for hedonic $\left(\chi^{2}=2.640, p=0.10\right)$ and utilitarian characteristics $\left(\chi^{2}=1.016, p=0.31\right)$. Table II does the same for products with high and low UX scores. Here, we found a significant difference for hedonic characteristics $\left(\chi^{2}=13.316, p<0.001\right)$, and a marginally significant difference for utilitarian characteristics $\left(\chi^{2}=3.668, p=0.06\right)$. More than half of the products with positive scores for UX had hedonic characteristics, while only about a quarter of the products with negative scores for UX had hedonic characteristics. Relatively more products with negative scores on UX had utilitarian characteristics than products with positive scores on UX. This finding suggests that UX is more easily applicable to hedonic products than to utilitarian products.
A second set of analyses involves the product scores in the questionnaire. We used Analysis of Variance, with Tukey's HSD as post hoc test, to investigate possible differences between products in each quadrant. To control for effects of hedonic and utilitarian product characteristics, we also included them as independent variables. Table III summarizes our findings.

Regarding participants' overall assessment of the products, we found that UX is a decisive factor, but that usability plays an additional role in differentiating within the group of products with high UX $\left(F(3,150)=39.17, p<0.001, \eta^{2}=0.44\right)$. Furthermore, a small effect was found for hedonic product characteristics $(\mathrm{F}(1,150)=7.98, p<0.05$, $\left.\eta^{2}=0.03\right)$ : Products with hedonic characteristics received higher assessments than products without (6.3 versus 5.6). No effects for utilitarian characteristics and no interaction effects were found.

With regard to the products' importance in daily life, usability appeared to be a relevant factor ( $\mathrm{F}(3$, $\left.150)=5.91, p<0.001, \eta^{2}=0.11\right)$ : The two quadrants with low usability scored significantly lower than the upper-right quadrant (high usability, high UX), while the lower-right quadrant (high usability, low UX) took an in-between position. No effects were found for hedonic and utilitarian characteristics, but a significant interaction effect between quadrants and utilitarian characteristics $\left(\mathrm{F}(2,150)=5.96, p<0.01, \eta^{2}=\right.$ 0.06 ) suggests that in the upper left quadrant (low usability, high UX), nonutilitarian products are more important to participants than utilitarian ones (3.4 versus 2.5), whereas in the other quadrants, utilitarian characteristics contributed positively to the importance of products.

Concerning the proportion of functionality used, we also found that usability matters $(F(3,150)=5.07$, $\left.p<0.005, \eta^{2}=0.08\right)$ : The two quadrants with high usability scored significantly better than the lower left quadrant (low usability, low UX), while the upper left quadrant (low usability, high UX) had an intermediate position. No effects of hedonic and utilitarian characteristics and no interaction effects were found.

Regarding the perceived importance of usability, one significant difference was found $(F(3,150)=$ 4.88, $\left.p<0.005, \eta^{2}=0.09\right)$ : Usability was considered to be less important for products in the upper left quadrant (low usability, high UX) than for those in the other quadrants. This finding 
TABLE III

MEAN SCORES OF PRODUCT CHARACTERISTICS IN THE Four QuAdRANTS

\begin{tabular}{lcccc}
\hline & $\begin{array}{c}\text { Upper right: } \\
\text { High usability, high } \\
\text { UX }\end{array}$ & $\begin{array}{c}\text { Upper left: } \\
\text { Low usability, high } \\
\text { UX }\end{array}$ & $\begin{array}{c}\text { Lower right: } \\
\text { High usability, low } \\
\text { UX }\end{array}$ & $\begin{array}{c}\text { Lower left: } \\
\text { Low usability, low } \\
\text { UX }\end{array}$ \\
\hline $\begin{array}{l}\text { Overall assessment } \\
\begin{array}{l}\text { Importance in daily } \\
\text { life }\end{array}\end{array} \mathbf{l}^{\mathrm{a}}$ & $3.7^{\mathrm{a}}$ & $6.8^{\mathrm{b}}$ & $5.0^{\mathrm{c}}$ & $4.2^{\mathrm{c}}$ \\
$\begin{array}{l}\text { Use of all } \\
\text { functionality }\end{array}$ & $3.6^{\mathrm{a}}$ & $2.8^{\mathrm{b}}$ & 3.4 & $2.5^{\mathrm{b}}$ \\
$\begin{array}{l}\text { Importance of } \\
\text { usability }\end{array}$ & $4.4^{\mathrm{a}}$ & 3.3 & $3.4^{\mathrm{a}}$ & $2.6^{\mathrm{b}}$ \\
Importance of UX & 4.0 & $3.6^{\mathrm{b}}$ & $4.4^{\mathrm{a}}$ & $4.6^{\mathrm{a}}$ \\
\hline
\end{tabular}

Note: Overall assessment measured on a ten-point scale $(1=$ negative, $10=$ positive $)$; all other variables measured on a five-point scale $(1=$ negative, $5=$ positive $)$. Significant differences $(p<0.05)$ indicated by different letters in superscript.

TABLE IV

Typical Comments ABOUT THE UPPER-RIght QuAdRANT (High Usability, High UX)

\begin{tabular}{|c|c|}
\hline Comment (product) & Comment (quadrant) \\
\hline $\begin{array}{l}\text { "It just does exactly what you would expect of it.... If I } \\
\text { want something, I immediately know how to do it, even if } \\
\text { l've never done it before, it's very intuitive on that } \\
\text { account." }\end{array}$ & $\begin{array}{l}\text { "They can do exactly what I want, and they do that } \\
\text { without problems." }\end{array}$ \\
\hline $\begin{array}{l}\text { "It is easy to use, it just works well, and it is just } \\
\text { exceptional for a washing machine to work for such a } \\
\text { long time, and you really only get that with that specific } \\
\text { brand. I can appreciate that." }\end{array}$ & $\begin{array}{l}\text { "... they work the way you want them to work; there is } \\
\text { nothing really strange going on: If you get them, they } \\
\text { do what you would expect. You would never return } \\
\text { them to the store." }\end{array}$ \\
\hline
\end{tabular}

suggests a compensating role of UX for judgments about usability.

In contrast, no significant differences were found for the perceived importance of UX. In this case, however, a significant difference was found for hedonic product characteristics $(\mathrm{F}(1,150)=5.76$, $\left.p<0.05, \eta^{2}=0.04\right)$ : UX was considered to be more important for hedonic products than for non-hedonic ones (4.2 versus 3.6).

\section{Qualitative Results: Exploring the Quadrants}

In the interviews, participants shed more light on their reasons for placing the products in the grid. We will now discuss the findings by quadrant.

The upper-right quadrant (high usability, high UX) features the highest number of products and much variety in product categories. However, the products have similarities that define the quadrant as a whole. (See Table IV for typical comments.)
Most products in this quadrant are important to users. We distinguish the following three broad categories.

1. General products that are used daily and are considered to be a necessity by many participants (e.g., computers and smartphones)

2. Communication technologies that allow them to stay in contact with friends and family (e.g., instant messaging apps)

3. Products used for entertainment that provide an easy form of leisure (e.g., game consoles, e-readers, and televisions)

Almost all products perform their intended functions without problems that hinder their use. Participants claimed that these products "do what they are supposed to do," and that most of them work intuitively. Intuitiveness was generally described as the extent to which users can find the functions of a product where they expect them to be, or can use the product without explanation. 
TABLE V

Typical Comments ABout THE LOWER LeFT QuAdRANT (LOW UsABILITY, LOW UX)

\section{Comment (product)}

“... it just doesn't work, so if you start it up, you first have to connect the controllers to the device, or it doesn't work, or the batteries are empty, every time ...."

"It has a lot of functions that I can't really use, of which I think they are unnecessary, and the menus are also very annoying."

\section{Comment (quadrant)}

"... they are actually the things that don't do what you want them to do. That don't work, or don't work properly, and they do that in a very annoying way."

"Things that indeed work slowly, that have extra layers which you have to work through; hidden things that you have to search for."

TABLE VI

Typical COMments ABOUT the UPPER LEFT QUADRANT (LOW USABILITY, High UX)

\section{Comment (product)}

"... it is a very nice product to work with, because the outcome that it gives is often satisfying. In the sense that you say: Yes, good. I made something nice ... something productive."

"... it gives that quality, which I like, but in order to set it up, you need some amount of knowledge, which I didn't really have at first."

\section{Comment (quadrant)}

"They all require some knowledge before you can really use them well. You have to kind of put some extra effort into it, but once you've done that, then they do what you want them to do."

"... they are also things that do what I need, and they do it well, but I think that there are possibilities for them to work better or more easily."
Within the quadrant, the most positively rated products are the ones that are used most often, are most important, or serve entertaining purposes.

The lower left quadrant (low usability, low UX) also has clear similarities. (See Table V for typical comments.) Almost all products listed here are frustrating to work with, because problems disturb their use to such an extent that users either must have very pressing reasons for still using them or have stopped using them. As these products do not fulfil the users' needs and are generally unpleasant to work with, this quadrant can be seen as the opposite of the upper-right quadrant.

Many of the products in this quadrant do not function well. Other issues involve a lack of control by the user, for instance, because of an unclear interface, slowness, or unwanted functions that are forced upon the user. Another problem with some of the products was that the tasks associated with them involve things that participants would rather not do (such as office work). Tasks and contexts of products can thus influence how users think about them.

Differences within the quadrant are mainly caused by the severity of the problems and the amount of frustration caused. Some participants stated that the frequency of using the products also leads to differences, since having to use a flawed product often means encountering its problems more frequently.

Products in the upper left quadrant (low usability, high UX) can generally be divided into two groups. (See Table VI for typical comments.) The first consists of products that, according to participants, require a certain amount of knowledge or effort before they can be properly used. These products were not seen as userfriendly but actually do perform their functions well. They are similar to the products in the upper-right quadrant (high usability, high UX) in the sense that they satisfy the users' needs. The main difference is that users cannot immediately start using them effectively. In the "utilitarian" category, an example is a software package that is effective but difficult to master; in the "hedonic" category, it can be an electric guitar. In most cases, participants did not expect the products to be easy to use due to their complicated nature or purpose. Some even mentioned that investing time and effort contributes to more satisfying or rewarding results, which enhance their experience with the products.

The second group consists of products that combine problem-free daily use with difficulties in specific incidental procedures (such as installation). For example, some televisions are not 
TABLE VII

Typical COMments ABOUt THE LOWER-Right QuAdRANT (High UsabILITY, LOW UX)

\begin{tabular}{ll}
\hline Comment (product) & Comment (quadrant) \\
\hline "It makes good coffee and it is quite user-friendly, but it is still & "They both have a failure in it. The concept is \\
annoying that is makes too little coffee." & $\begin{array}{l}\text { quite good in a sense, and if it works, it's perfect, } \\
\text { but then they don't work." }\end{array}$ \\
$\begin{array}{ll}\text { "It does work, but not often enough, and though it is a bit user- } \\
\text { friendly, the fact that it often doesn't work is kind of the reason to things that I don't look forward to. } \\
\text { not give it a really high grade." }\end{array}$ \\
\hline
\end{tabular}

user-friendly due to complicated menu structures but work well once they are installed correctly. Other examples were difficult-to-navigate software packages.

Differences within the quadrant involve the distinction between both groups: Users would have liked the latter group of products to work better, but this was not the case for the products with a learning curve. Most products with a learning curve were expected to be difficult to use, and participants usually had a certain motivation to learn how they work. Other differences related to the varying complexity or purposes of products: Less complex products or products that serve entertaining purposes tended to be judged more positively within the quadrant.

In the lower-right quadrant (high usability, low $\mathrm{UX}$ ), there is much similarity among the products: Most are quite simple and do not have too many functions. (See Table VII for typical comments.) They have an easy-to-use interface, usually with only a few buttons. Like the products in the lower left quadrant (low usability, low UX), almost all products in this quadrant have troublesome defects or failures that obstruct their use.

The problems of the products in this quadrant range from minor functional issues to the product not working at all. Many products were not what the user would have liked them to be but are still used because there is no better alternative.

Examples are a coffee machine that does not make the correct amount of coffee or a drilling machine that works properly only on wood. Problems with products without such defects mostly involve unwanted features or additions. Examples are software products with built-in ads and software with unwanted features, such as automatically changing documents in certain ways. Some participants also named products that work correctly, but are associated with tasks or contexts that are not enjoyable. Apart from work-related products, an example is a vacuum cleaner that works properly, but the user simply does not enjoy using it.

Differences within the quadrant were mainly caused by the severity of the defects or failures. The more issues that interrupt use, the more negatively a product was judged. Other factors were differing associations with the context of use and the amount of control users have over these suboptimal products.

\section{Qualitative Results: Usability and UX}

Conceptions Throughout the interviews, but particularly during the last two questions, participants reflected on the concepts of usability and UX, and their interrelation.

Concerning usability, most participants agreed that the concept mainly involves how easy a product is to use (see Table VIII). According to them, good usability means that you can use the functions of a product without too many things getting in the way. Terms that were often used to describe this included "intuitive," "clear," and "logical," which suggest that users can find functions where they expect them to be and that they can immediately start using a product. Other terms sometimes used in describing usability are "durability," "aesthetics," and "adaptability." Adaptability means gaining control over a product so that it becomes more suitable to the user's needs.

Confusing elements, such as unclear buttons or complex interfaces, are the main source of poor usability. Unwanted features can also lower usability, as they threaten users' control over a product. Requiring prior knowledge to use a product may worsen usability but is not always considered to be a bad thing. In some cases, participants judged complex products to be user-friendly. This finding may be explained by 
TABLE VIII

KEYWORDS AND COMMENTS ON USABILITY

\begin{tabular}{ll}
\hline Keywords & Comments \\
\hline $\begin{array}{l}\text { Clarity } \\
\text { Intuitiveness }\end{array}$ & "I think that what makes good user-friendliness is a clear overview of options, so \\
that it feels very intuitive." & "... you should not be busy with the product, so to speak. You should be busy \\
Fase & with the task, and if something gets in the way, its big buttons, or strange \\
functions, or weird Ul transitions that you completely do not want, then that is kind \\
fdaptability & of annoying." \\
Balance & "Good user-friendliness is that you are able to intuitively, without the use of a \\
Forcedness & manual, reach the functions that are in it, and use the product in the way that it is \\
Errors & supposed to be used." \\
Confusion &
\end{tabular}

TABLE IX

KEYWORDS AND COMMENTS ON UX

\begin{tabular}{ll}
\hline Keywords & Comments \\
\hline $\begin{array}{l}\text { Functioning } \\
\text { Purpose }\end{array}$ & $\begin{array}{l}\text { "Good experiences, I believe those mainly occur because it does what it } \\
\text { supposed to do, or what you kind of expect from it, and that it works a lo } \\
\text { reasonably long time." }\end{array}$ \\
$\begin{array}{l}\text { Dependability } \\
\text { Enjoyment }\end{array}$ & "That it works according to expectations, and if it does something on \\
$\begin{array}{l}\text { Accessibility } \\
\text { top of that ... then of course, it becomes completely positive." }\end{array}$ & "... mainly that it correctly does what you buy the product for and what \\
Satisfaction & it is actually supposed to do ... that it doesn't easily break, or that, for \\
Outcome & \\
Value & \\
Frustration & \\
Annoyance & \\
\end{tabular}

differing levels of expectations and the specific purposes of products. Some participants indicated that these products are more user-friendly compared to their competitors. Products may also become more usable over time as users learn to work with them.

Concerning UX, most participants simply described this concept as meaning that a product works, that it does what it is supposed to do (see Table IX). The product either carries out the function it was built for or does what the user wants it to do. A product with a good UX can be used without encountering any problems or errors. The category of a product plays an important role in UX, as many participants agreed that entertainment products in general provide a better experience than household products. The task that will be performed with a product and the context in which this takes place also tie in with this finding. Other often mentioned factors that can improve UX are "aesthetics," "dependableness," "accessibility," "trust," "outcome," "satisfaction," and "user support."

Frustration and annoyance are among the things that can hamper UX. The most mentioned problems were defects that cause a product not to work, navigational problems, poor durability, and unwanted features. Expectations appear to play an important role. For many participants, a product with a good UX meets or even exceeds their expectations. Products that do not meet expectations are disappointing and not motivating to use.

Regarding the relationship between usability and UX, participants confirmed that there is some degree of overlap between the two concepts. Both 
TABLE $X$

COMMENTS ON THE RELATIONSHIP BETWEEN USABILITY AND UX

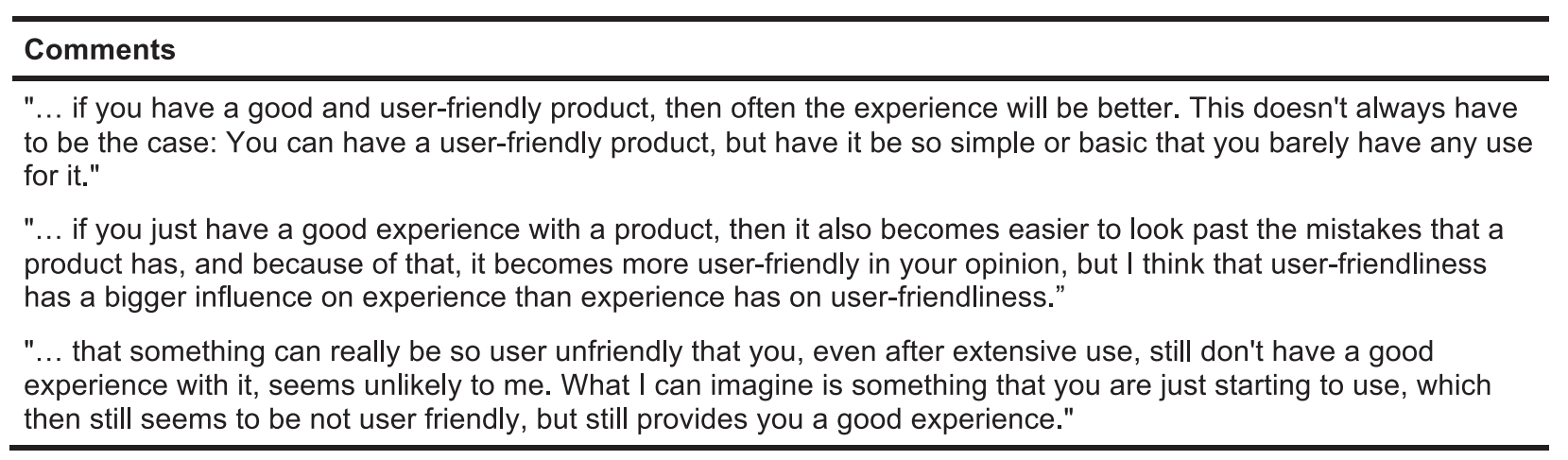

share some keywords and have comparable features. This fact was recognized by many participants, who explicitly discussed the relationship between usability and UX (see Table X).

The most commonly mentioned relationship is that usability can influence UX or that UX consists of many different qualities, including usability. Participants argued that a product that is userfriendly will often result in a good experience. Some described this relationship the other way around, stating that it would be unlikely for a product to be user-unfriendly but still produce a positive UX. However, since UX includes other factors as well, usability cannot guarantee a positive UX. UX is therefore seen as an overarching concept. Some participants identified a possible relationship that contrasts with the previous one, stating that a good UX can (indirectly) influence user-friendliness:

Having a positive UX can make it easier for users to accept flaws in the product's usability.

\section{Discussion}

With the research described in this paper, we tried to enrich the literature about usability and UX with empirical findings representing users' perspectives on specific products. We will first provide a brief overview of the main findings, and then present our conclusions about the concepts of usability and UX and their interrelation. At the end, we will discuss the limitations of our study, and present suggestions for future research.

Main Findings The grid that we devised on which participants had to place up to eight products made it possible to identify four different usabilityUX configurations. In two quadrants, UX and usability scores are roughly in line with each other. The positive quadrant on the upper right (high usability, high UX) involves products in three broad categories (indispensable products, products that facilitate communication with others, and entertainment products) that work relatively flawlessly. The negative quadrant on the lower left (low usability, low UX) involves products that do not work properly and cannot be fully controlled by users.

The other two quadrants provide more thoughtprovoking findings. Products placed in the lower-right quadrant (high usability, low UX) emphasize that usability cannot be seen as a sufficient condition for UX. Even when users are positive about a product's usability, its UX score can still be low. This may be the case when a product, even when perfectly operable, does not do its job well or when the very nature of the product cannot be easily connected with an outstanding positive experience. Products placed in the upper left quadrant (low usability, high UX) demonstrate that usability cannot be viewed as a necessary condition for UX. In the case of products with an (accepted) learning curve, users understand (and may even appreciate) that the correct use of the product requires time and effort. The same applies to products that offer great value to users in recurring activities but still need improvement in specific incidental procedures. The desired improvements involve nonrecurring activities, such as installation, whereas the product's principal value lies in its regular use.

When users define the concepts of usability and UX and reflect on their interrelation, it becomes clear that UX gets a less emotional and more instrumental interpretation than is true in some of the available definitions [16], [30], [31]. Participants generally recognize that usability can contribute to UX; some also state that a positive UX may make people more tolerant of usability problems. 


\section{CONCLUSION}

Our findings lead to several conclusions about the relationship between usability and UX. Concerning the first research question on how users conceptualize usability and UX, a first conclusion involves the rather instrumental nature of participants' conceptions of usability and UX.

Regarding usability, participants focused more strongly on effectiveness and efficiency than on satisfaction. Effectiveness and efficiency are the core of the construct, and participants seemed to move from there in two directions: To specific product characteristics (such as intuitiveness, aesthetics, and balance) that affect effective and efficient use, or to the feelings of satisfaction resulting from effective and efficient use.

Regarding UX, participants paid much attention to the way that the product works: Does it work as intended, as expected, without flaws or obstructions? From there, they sometimes moved to short-term affective responses (such as enjoyment or annoyance), and long-term evaluative responses (such as dependability and value) [46]. This rather instrumental perspective on UX contradicts the notion that UX shifts the attention to noninstrumental factors [33], but fits with UX being an overarching concept for product quality. The instrumental emphasis could be explained by the mixture of hedonic and utilitarian products selected by the participants. Given the aforementioned difference in meaning of UX between hedonic and utilitarian products, participants may have tried to look for common ground for different types of products and ended up with the very generic focus on whether the product works.

A second conclusion involves the situatedness of both usability and UX. In the interviews, it became clear that users often contextualize their views on the usability and UX of the products they use. One way of doing so involves comparisons with expectations, which may be based on comparisons with competing products or on their own estimations of, for instance, the complexity or tediousness of performing tasks with the product or of the maximally feasible outcomes of working with the product. UX also seems to be influenced by the specific context in which the product is normally used. This finding is in line with those of earlier research [12], [26], [42].

A third conclusion is that, according to the user's perspectives, the concept of UX seems to be better suited for hedonic products than for utilitarian products. This finding follows from our quantitative analyses (with significantly higher UX scores for hedonic products and marginally significant lower UX scores for utilitarian products), but also from the qualitative descriptions of products in the four quadrants. While the concept of usability seems to be equally applicable to utilitarian and hedonic products, hedonic products appear to have an advantage when users reflect on UX. For strictly utilitarian products, such as vacuum cleaners or office software packages, participants often struggled with the applicability of UX. Some of the problems of the concept of UX may have to do with the different ways in which the concept relates to hedonic and utilitarian products. In terms of Herzberg's dual-factor theory, UX can be seen as a motivational factor (the presence of positive emotions) for hedonic products, whereas it may primarily be a hygienic factor (the absence of negative emotions) for utilitarian products [47], [48].

Concerning the second research question on how users see the relationship between usability and UX, the first overall conclusion is that the relation between usability and UX is far from straightforward. This finding is indicated by the weak positive correlation between products' scores on the two concepts, as well as by the qualitative descriptions of products in the two quadrants with unbalanced usability and UX scores. Usability can be expected to contribute to UX, but products with high usability scores may still have a problematic UX, and products with low usability scores may end up with high UX scores. It, therefore, seems useful to consider both concepts as separate but related entities in the design process of products.

A second conclusion involves the importance of both concepts. It is generally assumed-as it was by our participants-that UX is an overarching concept and that usability is either part of it or contributes to it. Indeed, UX appears to be strongly related to the users' overall appreciation of products. Nevertheless, our findings provided various reasons not only to focus on UX, but also to consider usability as an important product characteristic. In our quantitative analyses, we found that usability (not UX) is related to the importance of products in people's everyday lives and to the extent to which users make use of all functionality of a product, which in the long run may be expected to contribute to overall appreciation. We also found that usability contributes to overall appreciation within the group of products with a positive UX score. 


\section{Limitations and Future Research Suggestions}

This is a first study into users' conceptions of usability and UX. Some limitations should be kept in mind. First of all, the data were collected using a limited sample of participants, characterized by their relative youth and relatively high educational level. The question remains whether our findings also apply to other groups of users. It is possible that older or less educated users have less clear demarcations of the two concepts and define their relationship differently. Future research could focus on comparisons between different groups of users, or on a comparison between users and experts. The grid used in our study appears to work well for this type of research.

Furthermore, our participants were asked to list eight products within the one-hour research session. Though this proved to be very doable for almost all participants, it may be beneficial for future research if participants are given the opportunity to think longer about the products they select and to reflect on their feelings and experiences with them. By allowing more time for the research process, additional insights that may have been missed within the current research could be gained.
Another limitation is that our study attempted to sketch a broad and general picture, including many different types of hedonic and utilitarian products. This is a useful approach for a first study in this area, but future research could focus on more specific types of products (e.g., hedonic versus utilitarian), or even on specific product categories (e.g., games, serious apps, or office software), and reflect on the usability-UX configurations within such groups of products.

Finally, it should be noted that our data were limited to the perceptions of the users. It would be interesting to also include observable actions in follow-up research. For usability, this would enrich the findings with a distinction between actual and perceived usability. For user experience, the use of physiological measures may be considered [49], [50]. Such follow-up research would necessarily move away from the more or less holistic user impressions we collected in this study, and may need to focus on specific product categories. It would also enable us to see how the concepts and their relationships develop when users move from novice to expert status.

\section{References}

[1] W. Hart-Davidson, "What are the work patterns of technical communication?" in Solving Problems in Technical Communication, J. Johnson-Eilola and S. A. Selber, Eds. Chicago, IL, USA: Univ. Chicago Press, 2013, pp. 50-74.

[2] Y. Cleary and M. Flammia, "Preparing technical communication students to function as user advocates in a self-service society," J. Tech. Writing Commun., vol. 42, no. 3, pp. 305-322, 2012.

[3] B. Mirel, "Critical review of experimental research on the usability of hard copy documentation," IEEE Trans. Prof. Commun., vol. 34, no. 2, pp. 109-122, Jun. 1991.

[4] N. Loorbach, J. Karreman, and M. Steehouder, "Verification steps and personal stories in an instruction manual for seniors: Effects on confidence, motivation, and usability," IEEE Trans. Prof. Commun., vol. 56, no. 4, pp. 294-312, Dec. 2013.

[5] J. Redish, "Technical communication and usability: Intertwined strands and mutual influence," IEEE Trans. Prof. Commun., vol. 53, no. 3, pp. 191-201, Sep. 2010.

[6] C. Baehr, "Complexities in hybridization: Professional identities and relationships in technical communication," Tech. Commun., vol. 62, no. 2, pp. 104-117, 2015.

[7] C. Lauer and E. Brunberger, "Technical communication as user experience in a broadening industry landscape," Tech. Commun., vol. 63, no. 3, pp. 248-264, 2016.

[8] E. Schulz, J. Ramey, M. van Alphen, and W. Rasnake, "Discovering user-generated metaphors through usability testing," IEEE Trans. Prof. Commun., vol. 40, no. 4, pp. 255-264, Dec. 1997.

[9] S. Wirtz and E. M. Jakobs, "Improving user experience for passenger information systems. Prototypes and reference objects," IEEE Trans. Prof. Commun., vol. 52, no. 2, pp. 120-137, Jun. 2013.

[10] M. de Jong and P. J. Schellens, "Toward a document evaluation methodology. What does research tell us about the validity and reliability of evaluation methods?” IEEE Trans. Prof. Commun., vol. 43, no. 3, pp. 242-260, Sep. 2000.

[11] S. Elling, L. Lentz, and M. de Jong, "Combining concurrent think-aloud protocols and eye-tracking observations: An analysis of verbalizations and silences," IEEE Trans. Prof. Commun., vol. 55, no. 3, pp. 206-220, Sep. 2012.

[12] J. R. Lewis, "Usability: Lessons learned and yet to be learned," Int. J. Human Comput. Interact., vol. 30, no. 9, pp. 663-684, 2014.

[13] R. R. Johnson, M. J. Salvo, and M. W. Zoetewey, "User-centered technology in participatory culture: Two decades 'Beyond a narrow conception of usability testing," IEEE Trans. Prof. Commun., vol. 50, no. 4, pp. 320-332, Dec. 2007. 
[14] F. Pucillo and G. Cascini, "A framework for user experience, needs and affordances," Design Studies, vol. 35, no. 2, pp. 160-179, 2014.

[15] Systems and Software Engineering-Systems and Software Quality Requirements and Evaluation (SquaRE)—System and Software Quality Model, ISO/IEC 25010, 2011.

[16] Ergonomic of Human System Interaction-Part 210: Human-centered Design for Interactive Systems, ISO 9241-210, 2010.

[17] B. Shackel, "Usability-Context, framework, definition, design and evaluation," Interact. Comput., vol. 21, nos. 5/6, pp. 339-346, 2009.

[18] J. Forlizzi and K. Battarbee, "Understanding experience in interactive systems," in Proc. 5th Conf. Design Interact. Syst., Process., Pract., Meth., Technol., 2004, pp. 261-268.

[19] C. Lallemand, G. Gronier, and V. Koenig, "User experience: A concept without consensus? Exploring practitioners' perspectives through an international survey," Comput. Human Behav., vol. 43, pp. 35-48, 2015.

[20] H. Tokkonen and P. Saariluoma, "How user experience is understood," in Proc. Sci. Inf. Conf., 2013, pp. $791-795$.

[21] M. Hertzum, T. Clemmensen, K. Hornbæk, J. Kumar, Q. Shi, and P. Yammiyavar, "Personal usability constructs: How people construe usability across nationalities and stakeholder groups," Int. J. Human Comput. Interact., vol. 27, no. 8, pp. 729-761, 2011.

[22] J. Nielsen, Usability Engineering. Boston, MA, USA: Academic, 1993.

[23] J. Nielsen and J. Levy, "Measuring usability: Preference vs. performance, Commun. ACM, vol. 37, no. 4, pp. 66-75, 1994.

[24] Ergonomic Requirements for Office Work with Visual Display Terminals (VDTs)_Part 11: Guidance on Usability, ISO 9241-11, 1998.

[25] Software Engineering-Product Quality_Part 1: Quality Model, ISO/IEC 9126-1, 2001.

[26] J. Brooke, "SUS: A quick and dirty usability scale," Usability. Eval. Ind., vol. 189, no. 194, pp. 4-7, 1996.

[27] M. A. Umar and M. Ghazali, "Investigation into usability attributes for embedded systems testing," Int. J. Softw. Eng. Technol., vol. 1, no. 2, pp. 13-18, 2014.

[28] T. Jokela, J. M. Netta Iivari, and M. Karukka, "The standard of user-centered design and the standard definition of usability: Analyzing ISO 13407 against ISO 9241-11," in Proc. Latin Amer. Conf. Human Comput. Interact., 2003, pp. 53-60.

[29] L. Alben, "Defining the criteria for effective interaction design," Interactions, vol. 3, no. 3, pp. 11-15, 1996.

[30] J. A. Bargas-Avila and K. Hornbæk, "Old wine in new bottles or novel challenges? A critical analysis of empirical studies of user experience," in Proc. SIGCHI Conf. Human Factors Comput. Syst., 2011, pp. $2689-2698$.

[31] M. Hassenzahl and N. Tractinsky, "User experience. A research agenda," Behav. Inf. Technol., vol. 25, no. 2, pp. 91-97, 2006.

[32] M. Hassenzahl, "User experience (UX): Towards an experiential perspective on product quality," in Proc. 20th Int. Conf. Assoc. Francophone d'Interaction Homme-Mach., 2008, pp. 11-15.

[33] E. L.-C. Law, V. Roto, M. Hassenzahl, A. P. O. S. Vermeeren, and J. Kort, "Understanding, scoping and defining user experience: A survey approach," in Proc. SIGCHI Conf. Human Factors Comput. Syst., 2009, pp. 719-728.

[34] J. Michalco, J. G. Simonsen, and K. Hornbæk, "An exploration of the relation between expectations and user experience," Int. J. Human-Comput. Interact., vol. 31, no. 9, pp. 603-617, 2015.

[35] N. Bevan, "What is the difference between the purpose of usability and user experience evaluation methods?" in Proc. Workshop UXEM Interact., Uppsala, Sweden, 2009. [Online]. Available: http://www.nigelbevan.com/ papers/What_is_the_difference_between_usability_and_user_experience_evaluation_methods.pdf

[36] N. Bevan, "Extending quality in use to provide a framework for usability measurement," in Human Centered Design, M. Kurosu, Ed. Heidelberg, Germany: Springer, 2009, pp. 13-22.

[37] V. Roto, M. Obrist, and K. Väänänen-Vainio-Mattila, "User experience evaluation methods in academic and industrial contexts," in Proc. Workshop UXEM Interact., Uppsala, Sweden, 2009. [Online]. Available: http: / / citeseerx.ist.psu.edu/viewdoc/download?doi=10.1.1.150.1764\&rep=rep1\&type=pdf

[38] M. Kurosu, "Usability, quality in use and the model of quality characteristics," in Human-Computer Interaction: Design and Evaluation, M. Kurosu, Ed. New York, USA: Springer, 2015, pp. 227-237.

[39] N. Tractinsky, A. S. Katz, and D. Ikar, "What is beautiful is usable," Interact. Comput., vol. 13, no. 2, pp. 127-145, 2000.

[40] J. Sauer and A. Sonderegger, "The influence of product aesthetics and user state in usability testing," Behav. Inf. Technol., vol. 30, no. 6, pp. 787-796, 2011.

[41] S. Mahlke and G. Lindgaard, "Emotional experiences and quality perceptions of interactive products," in Human-Computer Interaction. Interaction Design and Usability, J. J. Jacko, Ed. Heidelberg, Germany: Springer, 2007, pp. 164-173.

[42] T. Clemmensen, M. Hertzum, J. Yang, and Y. Chen, "Do usability professionals think about user experience in the same way as users and developers do?," in Human-Computer Interaction-Interact 2013, P. Kotzé, G. Marsden, G. Lindgaard, J. Wesson, and M. Winckler, Eds. Heildelberg, Germany: Springer, 2013, pp. 461-478.

[43] M. Hertzum and T. Clemmensen, "How do usability professionals construe usability?," Int. J. Human Comput. Studies, vol. 70, no. 1, pp. 26-42, 2012.

[44] M. Hertzum, T. Clemmensen, K. Hornbæk, J. Kumar, Q. Shi, and P. Yammiyavar, "Personal usability constructs: How people construe usability across nationalities and stakeholder groups," Int. J. Human Comput. Interact., vol. 27, no. 8, pp. 729-761, 2011.

[45] Y. Jiang et al., "A cross-cultural study of how usability professionals experience the usability of everyday systems," in Proc. 17th World Congr. Ergon, 2009, paper 1OP1040, [Online]. Available: http:/ / citeseerx.ist.psu.edu/viewdoc/download?doi=10.1.1.418.3099\&rep=rep1\&type=pdf 
[46] E. L.-C. Law, P. van Schaik, and V. Roto, “Attitudes towards user experience (UX) measurement," Int. J. Human Comput. Studies, vol. 72, no. 6, pp. 526-541, 2014.

[47] F. Herzberg, Work and the Nature of Man. New York, USA: World Publishing, 1966.

[48] P. Zhang and G. M. von Dran, "Satisfiers and dissatisfiers: A two-factor model for website design and evaluation," J. Amer. Soc. Inf. Sci., vol. 51, no. 14, pp. 1253-1268, 2000.

[49] R. L. Mandryk, K. I. Inkpen, and T. W. Calvert, "Using psychophysiological techniques to measure user experience with entertainment technologies," Behav. Inf. Technol., vol. 25, no. 2, 2006, Art. no. 1410158.

[50] Q.-X. Qu, L. Zhang, W.-Y. Chao, and V. Duffy, "User experience design based on eye-tracking technology: A case study on smartphone APPs," in Advances in Applied Digital Human Modeling and Simulation (Advances in Intelligent Systems and Computing), vol. 481. V. Duffy, Ed. New York, USA: Springer, 2017, pp. 303-315.

Tim R. Haaksma received the M.Sc. (Hons.) degree in Communication Studies from the University of Twente, Enschede, the Netherlands, in 2015. After that, he worked as a Lecturer within the Communication Science program with the University of Twente. He is currently working on a front-end development traineeship for designing web applications.

Menno D.T. de Jong received the Ph.D. degree in Communication Science from the University of Twente, Enschede, the Netherlands, in 1998. He is currently a Full Professor of Communication Science with the University of Twente. In addition, he is the Chair with the Communication Science Department and Program Director of the Bachelor and Master Programs in Communication Science. Between 2009 and 2015, he served as the Editor of Technical Communication, the flagship journal of the Society for Technical Communication (STC). He has authored and coauthored in a broad range of academic journals. His research interests include the fields of technical and organizational communication. Prof. De Jong has been the recipient of various awards for his research, including two Landmark Paper Awards from the IEEE Professional Communication Society and the Ken Rainey Award for Excellence in Research from the STC.
Joyce Karreman received the Ph.D. degree in Technical Communication from the University of Twente, Enschede, the Netherlands, in 2004. Since then, she has been affiliated with this university. She teaches courses in document design, user support, and user-centered design processes. Her research interests include the design of instructive documents, user-centered design, and intercultural issues related to usability and user experience. She has presented her work at international conferences on technical and professional communication and has published in several journals. 